\title{
Depression in Chronic Kidney Disease and Hemodialysis Patients
}

\author{
C. P. Andrade, R. C. Sesso \\ Division of Nephrology, Department of Medicine, Federal University of São Paulo, São Paulo, Brazil \\ Email: cpandrad@terra.com.br \\ Received July $9^{\text {th }}, 2012$; revised August $12^{\text {th }}, 2012$; accepted September $11^{\text {th }}, 2012$
}

\begin{abstract}
Depression is the most common psychiatric condition in Chronic Kidney Disease (CKD), but there are few studies that analyzed this condition in patients in different phases of disease. This article aims to evaluated depression in CKD patients, comparing patients in different phases of disease. Methods: We evaluated 134 patients with CKD submitted to conservative ambulatory treatment, and 36 patients with end-stage renal disease undergoing hemodialysis (HD). To evaluate depression, we used the Beck Depression Inventory (BDI), and the Beck Depression Inventory-SF (BDI-SF), a subscale that allows evaluate only the cognitive aspects of depression. Functional capacity was evaluated using the Karnofsky Performance Scale, and clinical and sociodemographic variables were also investigated. Results: Using BDI, depression was identified in $37.3 \%$ of patients in conservative treatment and in $41.6 \%$ in HD patients $(p>0.05)$. This percentage reduced when the BDI-SF was used, to $11.1 \%$ in conservative CKD patients and $13.8 \%$ in HD patients $(p>0.05)$. Depression was associated with marital status, professional activity, income, comorbidities and functional capacity. Discussion: We observed high prevalence of depression in patients with CKD undergoing conservative or hemodialysis treatment. Depression was associated with some clinical and sociodemografic variables and with functional capacity.
\end{abstract}

Keywords: Depression; Chronic Kidney Disease; Predialysis; Hemodialysis

\section{Introduction}

Chronic kidney disease (CKD) is determined by the presence of kidney injury and by the level of renal function, assessed according to the glomerular filtration rate. Following the criteria proposed by the National Kidney Foundation, 2002, the $\mathrm{CKD}$ is divided into five stages, classified according to the degree of the patient's renal function. Until the fourth stage of the disease, the so-called "conservative treatment" is recommended. In more advanced stages, called end-stage renal disease (ESRD), i.e., when the kidneys can no longer maintain homeostasis of the body, the patient will depend on one of the modalities of renal replacement therapy (RRT): dialysis or kidney transplant.

Depression is characterized as one of the most assessed psychological aspects regarding studies on patients with renal failure; however, there is a difficulty in recognizing its true extent in this population. This is due to methodological variations among studies (such as the diversity of instruments applied, which does not allow a comparison of results) and the difficulty of diagnosis generated by similarity of somatic symptoms present in depression and uremic symptoms, which leads to an increased number of false-positive cases (Kimmel, 2001, 2002; Kimmel et al., 2008; Kimmel \& Peterson, 2006; Almeida \& Meleiro, 2000; Zimmerman, Carvalho, \& Mari, 2004).

The evaluation of depression in patients during early stages of CKD becomes important, since its influence on quality of life and mortality rates is demonstrated by the literature. However, most of the studies evaluating patients in terminal stage of the disease and research assessing patients under pre-dialysis treatment are scarce.

This study aimed to evaluate depression in patients under conservative treatment for $\mathrm{CKD}$, comparing them with patients undergoing hemodialysis. Sociodemographic and clinical variables were also evaluated.

\section{Subjects and Methods}

\section{Participants}

A total of 181 patients were randomly selected, including 144 with nondialytic CKD who were followed at the outpatient clinics of the Division of Nephrology, Federal University of São Paulo, São Paulo, Brazil, and 37 patients undergoing hemodialysis at the institution. Eleven subjects refused to participate. The CKD patients attending the outpatients clinics had an estimated glomerular filtration measured by the $24 \mathrm{~h}$ creatinine clearance between 60 and $10 \mathrm{ml} / \mathrm{min} / 1.73 \mathrm{~m}^{2}$. They received a routine conservative care for CKD not on dialysis including particularly a nutritional orientation for hypoprotein diet and antihypertensive treatment. Dialysis patients included had been on hemodialysis for more than 6 months and less than 6 years, undergoing a conventional program of 3 hemodialysis sessions per week, lasting 4 hours each. Patients were excluded if they did not consent to participate, were younger than 18 years or had hearing, speech or cognitive deficits that would impair their understanding of the questions. Additionally, patients with dementia, delirium or a history of psychiatric disorders were also excluded. The protocol was approved by the ethics committee of the institution, and all participants gave written informed consent to participate in the study.

\section{Procedures}

The participants were interviewed prior the medical visits or after the hemodialysis session in a separate room by 2 trained interviewers. 
Depression was evaluated using the Beck Depression Inventory (BDI), which consists of 21 items that evaluate depressive symptoms, with each question being scored from 0 to 3 (Beck \& Steer, 1993). This instrument has been extensively used for the assessment of patients with CKD (Watnick, Wang, Demadura, \& Ganzini, 2005; Craven, Rodin, \& Littlefield, 1998). Cognitive symptoms of depression were evaluated using the Beck Depression Inventory-Short Form (BDI-SF), which has been validated for the Brazilian population (Furlaneto, Mendlowicz, \& Bueno, 2005). A cutoff score $\geq 14$ was defined to characterize patients with moderate or severe depression.

Functional capacity was assessed using the Karnofsky Performance Scale which determines functional impairment in the performance of daily life activities, using a score ranging from 100 (indicating no evident disease) to 0 (indicating death) (Schag, Heinrich, \& Ganz, 1984). This instrument has been widely used in studies on patients with CKD (Sesso \& Yoshihiro, 1997; Craven et al., 1998).

Socioeconomic level was evaluated according to the criteria of the Brazilian Association of Research Companies, which are recognized in Brazil and divide the population into social classes A, B, C, D and E, with class A corresponding to the highest socioeconomic level (ABEPE, 2003). Other sociodemographic and clinical variables were also analyzed in an attempt to identify a possible association with depression.

\section{Statistcs}

The results are reported as percentages for categorical variables and as means \pm SD for continuous variables. The chisquare test or Fisher's exact test were used for the comparison of categorical variables. The Student's $t$-test, was used for statistical analysis of continuous variables. A $p$ value $<0.05$ was considered to indicate statistical significance.

\section{Results}

From 170 patients who participated in the study, 135 were under conservative treatment and 36 undergoing hemodialysis. The latter were older adults and the percentage of whites was lower in relation to those under conservative treatment. Patients undergoing hemodialysis were more likely to be professionally inactive than those on conservative treatment (Table 1).

Regarding clinical variables, we observed that patients undergoing hemodialysis showed higher number of comorbidities and laboratory examinations more altered than those under conservative treatment (Table 2).

Average values obtained by the Beck Depression Inventory (BDI) and the Beck Depression Inventory Short Form (BDI-SF) scales were greater for patients undergoing hemodialysis compared to the group under conservative treatment; although these differences were not statistically significant. For both groups, the average scores obtained by the BDI-SF were lower than those obtained by the BDI. Using a cut-off point of $\geq 14$ for depression, the percentage of depressed patients was higher among those undergoing hemodialysis, both on the evaluation made by the BDI and the BDI-SF. When we evaluated only the cognitive symptoms of depression (BDI-SF), the percentage of depressed patients decreased in both groups (Table 3).

When we assessed depression with the BDI among the patients on conservative treatment, some associations were found: higher prevalence of depression in retired patients or those
Table 1.

Sociodemographic characteristics of the sample according treatment of chronic kidney disease (CKD).

\begin{tabular}{|c|c|c|}
\hline \multirow[b]{2}{*}{ Variable } & \multicolumn{2}{|c|}{ Treatment of CKD } \\
\hline & $\begin{array}{c}\text { Conservative } \\
\mathrm{N}=134\end{array}$ & $\begin{array}{c}\text { Hemodialysis } \\
\mathrm{N}=36\end{array}$ \\
\hline \multicolumn{3}{|l|}{ Sex } \\
\hline Male & $77(57.5)$ & $20(55.6)$ \\
\hline Female & $57(42.5)$ & $16(44.4)$ \\
\hline Age, years & $58.8 \pm 16.4$ & $51.5 \pm 17.7^{*}$ \\
\hline \multicolumn{3}{|l|}{ Race } \\
\hline White & $107(82.3)$ & $23(63.9)^{*}$ \\
\hline Black/Mulatto & $23(17.7)$ & $13(36.1)$ \\
\hline Asian & $4(3.1)$ & $0(0)$ \\
\hline \multicolumn{3}{|l|}{ Marital Status } \\
\hline Single/divorced & $38(28.3)$ & $15(41.7)$ \\
\hline Married & $81(60.4)$ & $18(50.0)$ \\
\hline Widower & $14(10.4)$ & $3(8.3)$ \\
\hline \multicolumn{3}{|l|}{ Educational level } \\
\hline Illiterate & $12(9.0)$ & $4(11.1)$ \\
\hline Primary school & $78(58.2)$ & $22(61.1)$ \\
\hline Middle school & $26(19.4)$ & $7(19.4)$ \\
\hline High school & $18(13.4)$ & $3(8.3)$ \\
\hline \multicolumn{3}{|l|}{ Professional Activity } \\
\hline Active & $31(41.9)$ & $3(15.8)^{* *}$ \\
\hline Retired/sickness benefit & $35(47.3)$ & $14(73.7)$ \\
\hline Unemployed & $8(10.8)$ & $2(10.5)$ \\
\hline \multicolumn{3}{|l|}{ Housing } \\
\hline Alone & $12(8.9)$ & $3(8.6)$ \\
\hline With friends or relatives & $122(91.0)$ & $32(91.4)$ \\
\hline \multicolumn{3}{|l|}{ Individual income } \\
\hline None & $20(14.9)$ & $3(9.1)$ \\
\hline $1-2$ m.w. & $57(42.5)$ & $12(36.4)$ \\
\hline 3 - 5 m.w. & $34(25.3)$ & $11(33.3)$ \\
\hline$>5$ m.w. & $19(14.1)$ & $7(21.2)$ \\
\hline \multicolumn{3}{|l|}{ Economic class } \\
\hline $\mathrm{A} / \mathrm{B}$ & $21(30.4)$ & $7(31.8)$ \\
\hline $\mathrm{C}$ & $31(44.5)$ & $10(45.5)$ \\
\hline $\mathrm{D} / \mathrm{E}$ & $17(24.6)$ & $5(22.7)$ \\
\hline
\end{tabular}

Note: data are reported as numbers $(\%)$ or means \pm SD. Monthly m.w. (minimum wage): US $\$ 210 .{ }^{*} p<0.05,{ }^{* *} p<0.10$ for comparison between the groups. No significant differences were observed for the other variables. 
Table 2.

Clinical characteristics of the groups according to treatment of chronic kidney disease (CKD).

\begin{tabular}{|c|c|c|}
\hline \multirow[b]{2}{*}{ Variable } & \multicolumn{2}{|c|}{ Treatment of CKD } \\
\hline & $\begin{array}{c}\text { Conservative } \\
\mathrm{N}=134\end{array}$ & $\begin{array}{l}\text { Hemodialysis } \\
\mathrm{N}=36\end{array}$ \\
\hline \multicolumn{3}{|l|}{ Stage of CKD } \\
\hline $3(\mathrm{GFR}<60$ and $\geq 30 \mathrm{ml} / \mathrm{min})$ & $52(38.8)$ & - \\
\hline $4(\mathrm{GFR}<30$ and $\geq 15 \mathrm{ml} / \mathrm{min})$ & $55(41.0)$ & - \\
\hline $5(\mathrm{GFR}<15 \mathrm{ml} / \mathrm{min})$ nondialytic & $28(20.2)$ & - \\
\hline $5(\mathrm{GFR}<15 \mathrm{ml} / \mathrm{min})$ on hemodialysis & - & $36(100.0)$ \\
\hline $\begin{array}{l}\text { Time since diagnosis of CKD, } \\
\text { months }\end{array}$ & $42.1 \pm 48.5$ & $28.0 \pm 21.4^{*}$ \\
\hline Number of comorbidities & $1.2 \pm 1.1$ & $2.7 \pm 1.8^{* *}$ \\
\hline \multicolumn{3}{|l|}{ Comorbidities } \\
\hline Diabetes mellitus & $54(40.2)$ & $13(37.1)$ \\
\hline Cardiac disease & $42(31.3)$ & $23(63.8)^{* *}$ \\
\hline Peripheral vascular disease & $12(8.9)$ & $6(16.6)$ \\
\hline Cerebrovascular disease & $15(11.1)$ & $4(11.0)$ \\
\hline Respiratory disease & $9(6.7)$ & $1(2.8)$ \\
\hline Connective tissue or bone disease & $27(20.1)$ & $19(52.8)^{* *}$ \\
\hline $\begin{array}{l}\text { Non-vascular central nervous } \\
\text { system disease }\end{array}$ & $2(1.4)$ & $2(5.6)$ \\
\hline Walking deficit & $3(2.2)$ & $1(2.8)$ \\
\hline Gastro-intestinal disease & $4(2.9)$ & $21(58.3)^{* *}$ \\
\hline Liver disease & $7(5.2)$ & $0(0)$ \\
\hline Malignancy & $11(8.2)$ & $2(5.6)$ \\
\hline HIV serum positive & $1(0.7)$ & $0(0)$ \\
\hline Visual deficit & $28(20.9)$ & $7(19.4)$ \\
\hline \multicolumn{3}{|l|}{$\begin{array}{l}\text { Hospitalization during the last } \\
6 \text { months }\end{array}$} \\
\hline 0 & $110(84.7)$ & $28(82.4)$ \\
\hline 1 & $14(10.7)$ & $3(8.8)$ \\
\hline 2 or more & $6(4.6)$ & $3(8.8)$ \\
\hline \multicolumn{3}{|l|}{ Laboratory tests } \\
\hline Creatinine clearance, $\mathrm{ml} / \mathrm{min}$ & $28.0 \pm 13.3$ & $8.0 \pm 3.3^{* *}$ \\
\hline Hematocrit, \% & $37.5 \pm 11.5$ & $34.2 \pm 5.7$ \\
\hline Hemoglobin, g/dL & $12.5 \pm 1.9$ & $11.2 \pm 1.8^{*}$ \\
\hline Calcium, mmol/L & $1.6 \pm 1.7$ & $1.2 \pm 0.1^{* *}$ \\
\hline Phosphorus, mg/dL & $4.0 \pm 0.9$ & $4.3 \pm 1.6$ \\
\hline Urea, $\mathrm{mg} / \mathrm{dL}$ & $82.7 \pm 41.9$ & $137.6 \pm 30.5^{* *}$ \\
\hline Functional capacity (Karnofsky score) & $88.8 \pm 13.5$ & $85.1 \pm 11.2$ \\
\hline
\end{tabular}

Note: data are reported as numbers $(\%)$ or means $\pm \mathrm{SD} .{ }^{*} p<0.05,{ }^{* *} p<0.10$ for comparison between the groups. GFR $=$ glomerular filtration rate.
Table 3.

Prevalence of depression according to the treatment of chronic kidney disease.

\begin{tabular}{lcc}
\hline & $\begin{array}{c}\text { Conservative } \\
\mathrm{N}=134\end{array}$ & $\begin{array}{c}\text { Hemodialisys } \\
\mathrm{N}=36\end{array}$ \\
\hline BDI scores & $12.2 \pm 9.4$ & $15.0 \pm 11.3$ \\
BDI-SF scores & $6.1 \pm 6.0$ & $7.3 \pm 7.5$ \\
BDI & & \\
$\quad$ Depressed & $50(37.3)$ & $15(41.6)$ \\
$\quad$ Non depressed & $83(62.7)$ & $21(58.4)$ \\
BDI-SF & & \\
\multicolumn{1}{c}{ Depressed } & \\
$\quad$ Non depressed & $15(11.1)$ & $5(13.8)$ \\
\hline
\end{tabular}

Note: values are expressed as numbers $(\%)$ or means \pm SD. Values for $p$ were not significant for the comparisons between the groups. ${ }^{\S} \mathrm{n}$ of patients with value above or equal to 14

receiving illness aid and patients with cerebro-vascular disease. We also observed associations between depression and marital status, income, central nervous system diseases and functional capacity.

Among patients undergoing hemodialysis, depression was related to income, cardiovascular diseases and functional capacity (Table 4). The analyses using the BDI-SF showed similar results.

\section{Discussion}

In this study, we found a slightly higher percentage of depressive symptoms among patients undergoing hemodialysis compared to patients under conservative treatment of CKD $(41.6 \%$ vs $37.3 \%)$. In addition, the hemodialysis group had average scores of the BDI tending to be higher than the cut-off point for moderate and severe depression $(15.0 \pm 11.3$ vs $12.2 \pm$ 9.4 , respectively). Although there are a number of studies that evaluated depressive symptoms in end-stage renal disease patients, the existing data do not allow us to determine the actual extension of the problem since there has not been a standardization of the evaluations; the instruments measuring depression and the cut-off point to define it were distinct. Our results are in the same line with those by Hoth, Christensen, Ehlers, Raichle \& Lawton (2007); Tsai et al. (2012), all pointing at a high prevalence of depression and indicating the need for improvement of assessment tools and the treatment of depression in CKD patients. Studies that assessed patients under conservative treatment and compared different types of treatment are scarce and do not allow us to conclude about the relationship between depression and types of treatment for CKD. Kalender, Ozdemir, \& Dervisoglu (2007) identified a lower prevalence of depresssion in patients submitted to peritoneal dialysis (CAPD), followed by the group under conservative treatment and hemodialysis. By comparing incident patients undergoing hemodialysis (less than six months of treatment) with prevalent patients (over six months) Kimmel et al. (1996) did not find significant differences regarding prevalence of depression. Cohen, Patel, Khetpal, Peterson \& Kimmel (2007) have not observed differences between patients with CKD under conservative treatment and patients from other medical specialties, without CKD.

Studies point to the importance of evaluation of depression in 
Tabela 4.

Relationship between depression and sociodemographic and clinical variables in patients according treatment of chronic kidney disease (BDI scores).

\begin{tabular}{|c|c|c|c|c|}
\hline \multirow{2}{*}{ Variable } & \multicolumn{2}{|c|}{ Conservative } & \multicolumn{2}{|c|}{ Hemodialysis } \\
\hline & Depressed & Non depressed & Depressed & Non depressed \\
\hline Marital status & * & & & \\
\hline Single/divorced & $17(45.9)$ & $20(54.1)$ & $8(53.3)$ & $7(46.7)$ \\
\hline Married & $27(34.1)$ & $52(65.9)$ & $12(66.6)$ & $6(33.4)$ \\
\hline Widower & $4(28.5)$ & $10(72.5)$ & $2(66.6)$ & $1(33.4)$ \\
\hline Activity Professional & * & & & \\
\hline Active & $5(16.1)$ & $26(83.9)$ & $1(33.4)$ & $2(66.6)$ \\
\hline Retired/sickness benefit & $14(40.0)$ & $21(60.0)$ & $8(57.1)$ & $6(42.9)$ \\
\hline Unemployed & $4(50.0)$ & $4(50.0)$ & $1(50.0)$ & $1(50.0)$ \\
\hline Individual Income per month & * & & & \\
\hline None & $10(50.0)$ & $10(50.0)$ & $2(66.6)$ & $1(33.4)$ \\
\hline 1 to $2 \mathrm{~m} . \mathrm{w}$. & $25(44.6)$ & $31(55.4)$ & $6(50.0)$ & $6(50.0)$ \\
\hline 3 to 5 m.w. & $12(35.3)$ & $22(64.7)$ & $5(45.4)$ & $6(54.6)$ \\
\hline$>5$ m.w. & $2(10.5)$ & $17(89.5)$ & $0(0)$ & $7(100.0)$ \\
\hline \multicolumn{5}{|l|}{ Comorbidities } \\
\hline Cerebrovasc. disease & $10(71.4)^{* *}$ & $4(28.5)^{*}$ & $0(0)$ & $4(100.0)$ \\
\hline $\begin{array}{l}\text { Non-vasc. central } \\
\text { nervous system disease }\end{array}$ & $1(50.0)$ & $1(50.0)^{* *}$ & $2(100.0)$ & $0(0)$ \\
\hline Gastrointestinal disease & $2(50.0)$ & $2(50.0)$ & $12(70.5)$ & $9(69.5)$ \\
\hline Functional capacity & $81.6 \pm 15.9^{* *}$ & $92.6 \pm 10.3$ & $80.0 \pm 13.5^{*}$ & $88.8 \pm 7.5$ \\
\hline
\end{tabular}

Note: values are expressed as numbers $(\%)$ or means $\pm \mathrm{SD} .{ }^{*} p \leq 0.05 ;{ }^{* *} p \leq 0.01$ for the comparisons between depressed and non depressed patients. m.w. (Minimum wage) $=\mathrm{U} \$ 210$ per month. Only variables with a $p$ value $<0.05$ for the comparison between the groups are shown. Other clinical and sociodemographic variables were not significantly different between groups.

the early stages of the disease, since it is a significant predictor of adverse outcomes in the progression of CKD, beginning of the hemodialysis treatment, death and hospitalization (Tsai et al., 2012).

Our report and some other studies on hemodialysis patients have evaluated only the cognitive symptoms of depression, since the CKD presents a series of uremic symptoms that overlap those of depression. As seen in this study, there was a decrease in the average values of scales and percentages of depression by the BDI-SF in comparison to the complete BDI (Kimmel et al., 1996; Kimmel et al., 1998; Kimmel et al., 2000; Guzman \& Nicassio, 2003; Micozkadioglu et al., 2006; Kalender, Ozdemir, \& Koroglu, 2006; Kalender, 2007). This demonstrates the importance of the differential diagnosis of depression in these patients, since symptoms such as anorexia, insomnia, decreased sexual interest, and fatigue are present in both depressive and uremia disorders. These uremic symptoms may have misleaded the actual prevalence of depression in many studies that used only the BDI scale in renal disease patients. We have not found studies that had carried out the assessment of cognitive symptoms of depression in patients during the early stages of the disease.

In our study, depression was associated with worse functional capacity. Some studies also indicated the association between depression and functional capacity and classified this association as one of the risk factors for mortality in dialyzed patients. (Kalender et al., 2006; Barbosa, Andrade, \& Bastos, 2007).
At the same time, we observed a higher percentage of depressed patients among those who were unemployed and those without monthly income. We know that CKD brings a series of losses to the patient and requires some adaptation, including the difficulty of integration into the labor market, due to the physiccal condition caused by the decease and the dynamics of dialysis treatment. In our study, there were more patients professsionally inactive than in other Brazilian studies of end-stage renal disease, calling attention to the high percentage of inactive patients on the onset of dialysis treatment (Sesso et al., 1997; Sesso \& Gordan, 2007). This aspect deserves to be better evaluated in future studies.

A limitation of the present study was the relatively small size of the sample in order to detect significant differences between the groups studied. The cross-sectional design of the study only allowed us to determine associations between variables and not any causal relationship. In addition, some important clinical aspects for the assessment of depression - such as personal or family history and drug treatment for the disorder-were not evaluated. Anxiety symptoms and measures of quality of life were not assessed because they were not the main focus of the study.

This study has shown high rates of depressive symptoms in patients with $\mathrm{CKD}$, which alert us to the importance of the diagnosis of depression in early stages of the disease, leading to early treatment and better quality of life in the course of the disease.

Further studies need to be performed on patients in various 
stages of $\mathrm{CKD}$, so that we can better understand this disease and allow the improvement of diagnostic, preventive and therapeutic strategies.

\section{REFERENCES}

Almeida, A. M., \& Meleiro, M. A. S. (2000). Doença renal crônica: Uma revisão. Jornal Brasileiro de Nefrologia, 22, 192-200.

Associação Brasileira de Empresas de Pesquisa (ABEPE) (2003). Critério de classificação econômica Brasil. URL (last checked 18 January 2010). http://www.abep.org

Barbosa, L. M. M., Andrade Jr., M. P., \& Bastos, K. A. (2007). Preditores de qualidade de vida em pacientes com doença renal crônica em hemodiálise. Jornal Brasileiro de Nefrologia, 29, 222-229.

Beck, A. T., \& Steer, R. A. (1993). Beck depression inventory manual. San Antonio: Psycholgical Corporation.

Cohen, S. D., Patel, S. S., Khetpal, P., Peterson, R. A., \& Kimmel, P. L. (2007). Pain, sleep disturbance, and quality of life in patients with chronic kidney disease. Clinical Journal of American Society of Nephrology, 2, 919-925. doi:10.2215/CJN.00820207

Craven, J. L., Rodin, G. M., \& Littlefield, C. (1998). The Beck Depression Inventory as a screening device for major depression in renal di alysis patients. Internacional Journal of Psychiatry Medicine, 18, 365-374. doi:10.2190/M1TX-V1EJ-E43L-RKLF

Furlanetto, L. M., Mendlowicz, M. V., \& Bueno, J. R. (2005). The validity of the beck depression inventory-short form as a screening and diagnostic instrument for moderate and severe depression in medical inpatients. Journal of Affective Disorders, 86, 87-91. doi:10.1016/j.jad.2004.12.011

Guzman, S. J., \& Nicassio, P. M. (2003). The contribution of negative and positive illness schemas to depression in patients with end-stage renal disease. Journal of Behavior Medicine, 26, 517-534. doi:10.1023/A:1026249702054

Hoth, K. F., Christensen, A. J., Ehlers, S. L., Raichle, K. A., \& Lawton, W. J. (2007). A longitudinal examination of social support, agreeableness and depressive symptoms in chronic kidney disease. Journal of Behavior Medicine, 30, 69-76. doi:10.1007/s10865-006-9083-2

Kalender, B., Ozdemir, A. C., \& Koroglu, G. (2006). Association of depression with markers of nutrition and inflammation in Chronic kidney disease and end-stage renal disease. Nephrology Clinical and Practice, 102, c115-c121.

Kalender, B., Ozdemir, A. C., Dervisoglu, E., \& Ozdemir, O. (2007). Quality of life in chronic kidney disease: Effects of treatment modality, depression, malnutrition and Inflammation. International Journal of Clinical Practice, 61, 569-576.

doi:10.1111/j.1742-1241.2006.01251.x

Micozkadioglu, H., Micozkadioglu, I., Zumrutdal, A., Erdem, A. et al.
(2006). Relationship between depressive affect and malnutritioninflammation complex syndrome in haemodialysis patients. Nephrology, 11, 502-505. doi:10.1111/j.1440-1797.2006.00664.x

Kimmel, P. L., Peterson, R. A., Weihs, K. L., Simmens, S. J. et al. (1996). Psychologic functioning, quality of life, and behavioral compliance in patients beginning hemodialysis. Journal of American Society of Nephrology, 7, 2152-2159.

Kimmel, P. L., Peterson, R. A., Weihs, K. L., Simmens, S. J. et al. (1998). Psychossocial factors, bahavior compliance and survival in urban hemodialysis patients. Kidney International, 54, 245-254. doi:10.1046/j.1523-1755.1998.00989.x

Kimmel, P. L., Peterson, R. A., Weihs, K. L. et al. (2000). Multiple measurements of depression predict mortality in a longitudinal study of chronic hemodialysis outpatients. Kidney International, 57, 20932098. doi:10.1046/j.1523-1755.2000.00059.x

Kimmel, P. L. (2001). Psychossocial factors in dialysis patients. Kidney International, 59, 1599-1613. doi:10.1046/j.1523-1755.2001.0590041599.x

Kimmel, P. L. (2002). Depression in patients with chronic renal disease: What we know and what we need to know. Journal of Psychosomatic Research, 53, 951-956. doi:10.1016/S0022-3999(02)00310-0

Kimmel, P. L., \& Peterson, R. A. (2006) Depression in Patients with end-stage renal disease treated with dialysis: Has the time to treat arrived? Clinical Journal of American Society Nephrology, 1, 349-352. doi: $10.2215 /$ CJN.00890306

National Kidney Foundation (2002). K/DOQI clinical practice guidelines for chronic kidney disease: Executive summary. New York, 76-82.

Schag, C. C., Heinrich, R. L., \& Ganz, P. A. (1984). Karnofsky performance status revisited: Reliability, validity, and guidelines. Jour nal of Clinical Oncology, 2, 187-193.

Sesso, R., \& Yoshihiro, M. M. (1997). Time of diagnosis of chronic renal failure and assessment of quality of life in haemodialysis patients. Nephrology, Dialisis and Transplantation, 12, 2111-2116. doi:10.1093/ndt/12.10.2111

Sesso, R., \& Gordan, P. (2007). Dados disponíveis sobre a doença renal crônica no Brasil. Jornal Brasileiro de Nefrologia, 19, 9-12.

Tsai, Y. C., Chiu, Y. W., Hung, C. C., Hwang, S. J., Tsai, J. C., Wang, S. L., Lin, M. Y., \& Chen, H. C. (2012). Association of symptoms of depression with progression of CKD. American Journal of Kidney Disease, 60, 54-61. doi:10.1053/j.ajkd.2012.02.325

Watnick, S., Wang, P.-L., Demadura, T., \& Ganzini, L. (2005). Validation of two depression screening tools in dialysis patients. American Journal of Kidney Disease, 46, 919-924. doi:10.1053/j.ajkd.2005.08.006

Zimmermann, P. R., Carvalho, J. O., \& Mari, J. J. (2004). Impacto da depressão e outros fatores psicossociais no prognóstico de pacientes renais crônicos. Revista de Psiquiatria do Rio Grande do Sul, 26, 312-318. doi:10.1590/S0101-81082004000300008 